\title{
Modeling of a Series Hybrid Hydraulic Drivetrain for a Light-Duty Vehicle in Hopsan
}

\author{
K. Baer, L. Ericson, and P. Krus \\ Division of Fluid and Mechatronic Systems, Department of Management and Engineering, \\ Linköping University, Linköping, Sweden \\ E-mail: katharina.baer@liu.se, liselott.ericson@liu.se, petter.krus@liu.se
}

\begin{abstract}
Hydraulic hybrids continue to receive attention as a possible solution in the search for improved fuel economy for different vehicle types. This paper presents the development of a framework for hybrid hydraulic vehicles, using the Hopsan simulation tool of Linköping University's Division of Fluid and Mechatronic Systems (Flumes). This framework is then used on a series hydraulic hybrid transmission which employs a pump control based on the hydraulic accumulator's state-of-charge (SoC). Several simplifications were made, especially concerning mechanical components. Simulation over two urban standard cycles shows promising results concerning velocity error and energy recuperation potential, provided the components are sized appropriately to compensate for the mechanical limitations. This paper lays the foundation for the further development of a design framework suitable for optimizing the full drivetrain, including component sizing and controller parameterization.
\end{abstract}

Keywords: Series hydraulic hybrid model, Hopsan modeling

\section{Introduction}

Fuel economy continues to be a major challenge and focus in vehicle technology, both for economic and environmental reasons. As a possible solution, hybrid architectures keep being investigated for both passenger and larger vehicles. They have in common that another power source is added to the existing combustion engine including an energy storage component to allow for some form of energy recuperation; in the case of hybrid drivetrains it is the kinetic energy of the vehicle that would be lost in form of heat when braking. While this implies the addition of a number of components to the drivetrain, it potentially allows for down-sizing, and depending on the configuration, also optimized operation of the internal combustion engine.

Commercially available hybrid passenger vehicles are typically electric hybrids, one of the best-known examples being the Toyota Prius. These hybrids use batteries for storing the recuperated energy, which are advantageous in comparison to hydraulic accumulators in terms of energy density, allowing more energy to be stored. In comparison to that, hydraulic hybrids allow for a higher power density [1], which makes them especially interesting when frequent starts and stops occur, and a large vehicle mass is moved. Typical applications are heavier vehicles in urban traffic, such as busses [2], refuse vehicles [3] or delivery trucks [4]. But also passenger and light-weight vehicles are considered suitable for hydraulic hybrids [5][6].
To provide a framework for future research, a simulation model of a series hydraulic hybrid light-duty vehicle has been developed which will be presented in this paper. It is to be enhanced further to allow for a comprehensive optimization of the complete hybrid vehicle, and to be compared to other hydraulic hybrid architectures.

\section{Hybrid hydraulic drivetrains}

Three principle architectures can be found for hybrids: series, parallel and power-split. Their differences concern how the internal combustion engine is operated and whether highly efficient mechanical power transfer is possible. In hydraulic hybrids, at least one hydrostatic reversible unit (pump/motor) is used, acting as a motor on the wheels during acceleration and as a pump for energy recuperation during braking.

In a series hydraulic hybrid configuration, the engine drives a pump, which in turn drives the pump/motor and charges the system's accumulator if necessary. The pump/motor is then connected to the vehicle's axle. This way, the engine speed is decoupled from the wheel speed, allowing for a more efficient operating point. The engine can also be completely decoupled when including a clutch. Because of the energy conversion from mechanical to hydraulic to mechanical, the transmission is less efficient than an entirely mechanical drivetrain.

This mechanical connection between the internal combustion engine and the vehicle exists in the parallel hybrid ar- 
chitecture. The pump/motor is mounted between the engine and a mechanical transmission, and can provide additional torque to the wheels. The speeds of the engine and the wheels are coupled, and consequently optimal engine management is not possible. As the drivetrain does not require a complete redesign, the parallel hybrid architecture offers the possibility for reconfiguration of existing vehicles and drivetrains (e.g. as so-called add-on hybrids) [7][2].

A power-split configuration, sometimes also referred to as "hydro-mechanical hybrid", aims to combine the advantages of both series and parallel hydraulic hybrids through planetary gear sets. The engine power is split into a hydraulic and a mechanical path. The hydraulic system can add or take power from the drivetrain, and hydraulic and mechanical power are recombined before the wheels. This way, both optimal engine management and efficient mechanical power transfer can be realized. Depending on the number and location of the planetary gear sets, there are different configurations for power-split hydraulic hybrids [3] [4].

\section{Framework for a hybrid hydraulic drivetrain system design in Hopsan}

The model of the series hybrid hydraulic drivetrain is developed in Hopsan [8], a multi-domain system simulation tool. Its current generation is continuously being developed at the Division of Fluid and Mechatronic Systems in Linköping since 2009. Just like its predecessor, now referred to as "Hopsan Classic", Hopsan utilizes the transmission line modeling (TLM) technique and is available for download free of charge. For this paper, a development version has been used together with customized components.

The primary focus of the model is the hydraulic part of the drivetrain together with the vehicle, while the combustion engine driving the pump will be considered in the future. Here it is assumed to run at a constant speed. Furthermore, gearing is limited to the gear ratio of the vehicle's differential, without an additional gearbox. The lack of a gearbox does increase the system's efficiency due to reduced losses [1], but its inclusion could be beneficial for reducing the component sizes. The general structure of the model is given in Figure 1; the volumes and the rotary shaft used are connecting elements required by the underlying modeling technique. The main components will be explained below.

The vehicle is represented by a one-dimensional component model and described by the parameters total vehicle mass $M_{\text {veh,total }}$, effective front area $c_{d} \cdot A$ and wheel radius $r_{\text {wheel }}$, the latter being combined with the differential gear ratio $i_{\text {diff }}$ into what is referred to here as effective wheel radius $r_{\text {wheel,ee }}$ :

$$
r_{\text {wheel,e }}=r_{\text {wheel }} / i_{\text {diff }} \text {. }
$$

The component model takes into account the aerodynamic drag and rolling resistance acting on the vehicle, but neglects factors such as gradeability and driving turns. There is no difference between supplying power to the front or rear axle of the vehicle.

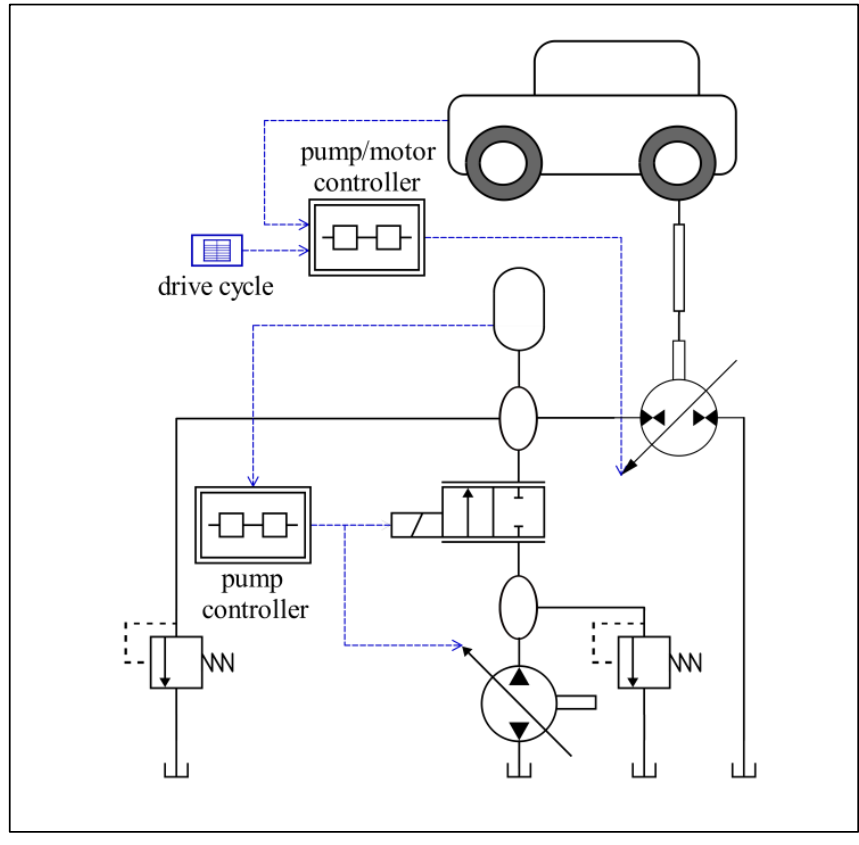

Figure 1: Basic model structure

$$
\begin{gathered}
T_{v e h, 1}+T_{v e h, 2}=r_{w h e e l, e} \cdot\left(M_{v e h, t o t a l} \cdot \dot{v}_{c}+\right. \\
\left.9.82 \cdot M_{v e h, \text { total }} \cdot c_{f r}+c_{d} \cdot A \cdot \rho \cdot v_{c}^{2} / 2\right),
\end{gathered}
$$

with $\mathrm{T}_{\mathrm{veh}, 1}$ and $\mathrm{T}_{\mathrm{veh}, 2}$ being the torques acting on the vehicle's axles, $v_{c}$ being the vehicle's current velocity, $c_{f r}$ the rolling resistance coefficient and $\rho$ the air density.

For the transmission, a variable pump and a variable pump/ motor are used. Both components contain a mathematical efficiency model by Rydberg [9], which determines the efficiency based on angular velocity, pressure, and displacement setting angle.

The model of the accumulator component is based on the polytropic law for a perfect gas, and further idealized assuming a loss-free component. For this model, an adiabatic process is assumed, and the accumulator not to be charged at the beginning of the operation.

The pump/motor's displacement setting angle is determined through a PI-controlled velocity feedback, with the drive cycle being simulated as reference input. The pump charging the system is switched on and shut off according to the accumulator's current state-of-charge (SoC) [10]: in the case of the accumulator state-of-charge $\mathrm{SoC}_{\mathrm{Acc}}$ falling below a defined minimum state-of-charge $\mathrm{SoC}_{\text {low }}$, the pump delivers a charge flow. It is shut down once a upper limit state-ofcharge $\mathrm{SoC}_{\text {high }}$ is reached in order to reserve accumulator capacity for energy recuperation. In the current accumulator model, this state-of-charge can be equivalently expressed as a function of the current filling volume, or of the pressure in the accumulator (cf. for example [11]). While Kim and Filipi [6] define an engine power corresponding to the state-ofcharge, here the power input is determined through the load on the pump and its constant speed. Even though the pump is fully variable, it is effectively either fully closed or fully opened, thus avoiding an operation in the low-efficiency low 
displacement setting angle range. The same controller also actuates a $2 / 2$ directional valve for the pump's protection.

The main hydraulic components' contribution to the vehicle's total weight $\mathrm{M}_{\mathrm{veh}, \text { total }}$ is considered in order for the model to be ultimately used in a full system optimization. For the variable pump and the accumulator, data of commercially available components are extrapolated continuously, while the pump/motor is described with discrete values of the next bigger available component size.

\section{Application example: Simulation of two urban drive cycles}

In this paper, a light-duty vehicle is modeled with the parameters according to Table 1 . As reference velocity profiles, two EPA driving schedules [12] were chosen in order to ensure the model is not only parameterized for one single drive cycle, cf. Figure 2. They are different in respect to duration, maximum and average speed, as well as the total distance traveled, even though both are representing urban velocity profiles.

Table 1: Light-duty vehicle data.

\begin{tabular}{|l|l|}
\hline Vehicle parameter & Value \\
\hline $\begin{array}{l}\text { Vehicle mass } \mathrm{M}_{\text {veh }} \text { (half-loaded, without } \\
\text { main hydraulic components) }\end{array}$ & $2700 \mathrm{~kg}$ \\
\hline Frontal area A & $3.75 \mathrm{~m}^{2}$ \\
\hline Aerodynamic drag coefficient $\mathrm{c}_{\mathrm{d}}$ & 0.475 \\
\hline Effective wheel radius $\mathrm{r}_{\text {wheel,e }}$ & $0.1 \mathrm{~m}$ \\
\hline
\end{tabular}

The sizes of the main components of the drivetrain, i.e. the hydraulic machines and the accumulator, as well as the controller settings are the same for both drive cycles. When evaluating the results of simulating the drive cycles, two different values are considered. On the one hand, as a measure of the accumulated relative velocity error, ARVE, the accumulated velocity deviation relative to the drive cycle's total covered distance is given, i.e.

$$
A R V E=\int_{t, \text { start }}^{t, \text { end }}\left|v_{c}-v_{\text {ref }}\right| d t / x_{\max },
$$

with $v_{\text {ref }}$ as the reference velocity according to the simulated drive cycle, and $\mathrm{x}_{\max }$ as the total distance covered by the respective drive cycle.

As an example, the results for simulating the FTP-72 cycle are given in Figure 3, showing that the vehicle follows the reference velocity very well, with the largest deviations occurring in acceleration phases.

\section{EPA Urban Dynamometer Driving} Schedule FTP-72

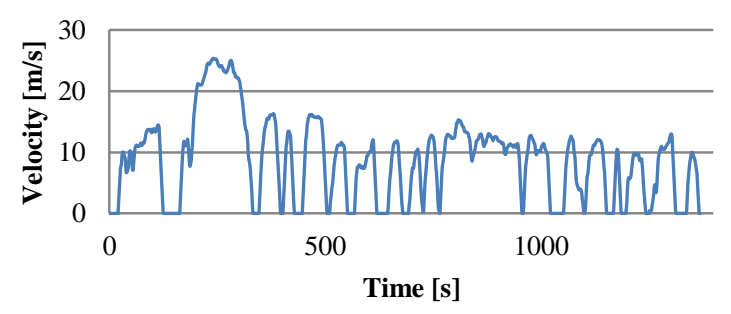

EPA New York City Cycle (NYCC)

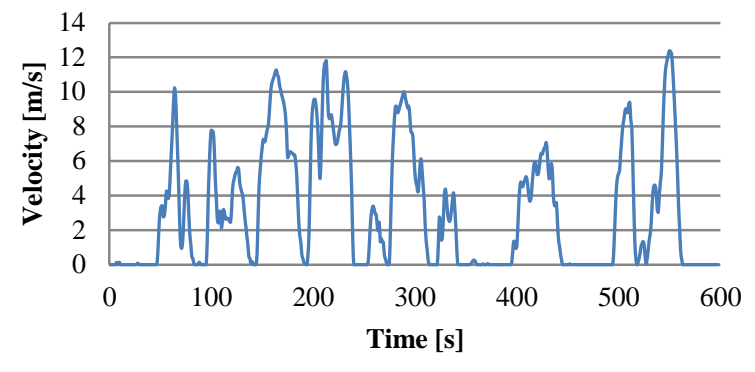

Figure 2: EPA Driving Schedules

EPA Urban Dynamometer Driving Schedule FTP-72
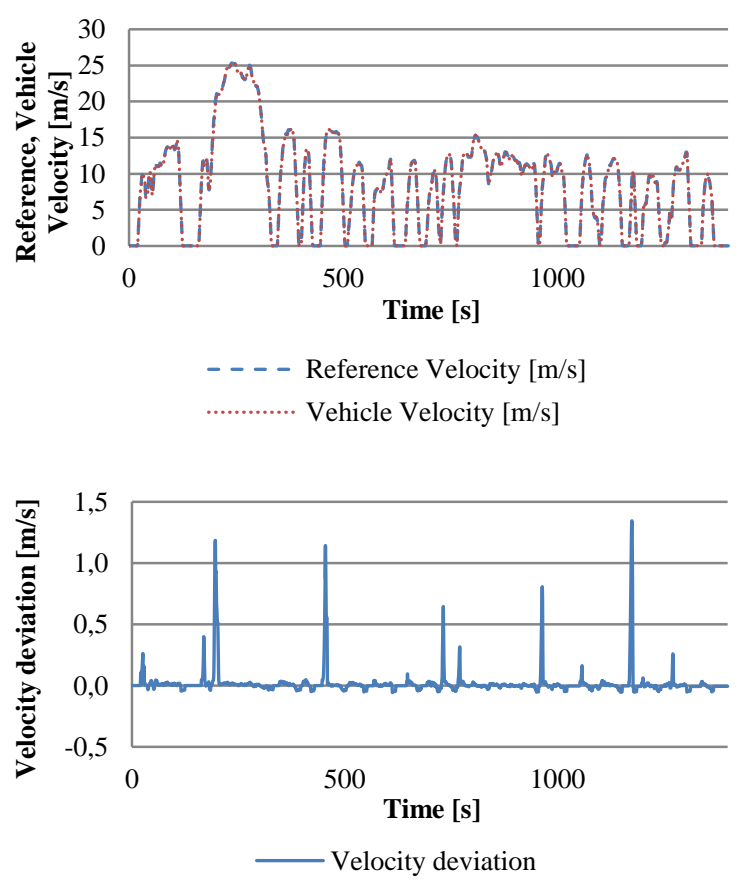

Figure 3: Simulation results for EPA UDDS FTP-72: Actual vehicle velocity vs. reference velocity; velocity deviation 
The effect of the accumulator's inclusion in the system on the energy consumption is expressed as the energy input ratio

$$
E I R=E_{\text {in }, \text { pump }} /\left(E_{\text {in,veh }}+E_{\text {loss }}\right),
$$

with $\mathrm{E}_{\mathrm{in}, \mathrm{pump}}$ as the energy provided to the pump, $\mathrm{E}_{\mathrm{in}, \mathrm{veh}}$ as the (positive) energy input into the vehicle, not accounting for the recuperated energy, and $\mathrm{E}_{\text {loss }}$ accounting for losses in the charge pump, the valve and the pump/motor when operating in motor mode. If there was no accumulator allowing for energy recuperation, this ratio would equal 1; the more energy recuperation occurs, the lower this value becomes.

The results for the simulation over both cycles are summarized in Table 2. As the values show, different driving schedules will lead to varying results.

Table 2: Simulation results for ARVE and EIR

\begin{tabular}{|c|c|c|}
\hline Drive Cycle & $\begin{array}{l}\text { Accumulated relative } \\
\text { velocity error }\end{array}$ & $\begin{array}{l}\text { Energy input } \\
\text { ratio }\end{array}$ \\
\hline FTP-72 & $0.385 \%$ & $68.81 \%$ \\
\hline NYCC & $3.259 \%$ & $75.65 \%$ \\
\hline
\end{tabular}

It should be noted that after completing the driving schedule, the final state-of-charge $\mathrm{SoC}_{\mathrm{f}}$ differs for both drive cycles (see Table 3). This effect has been neglected in the energy efficiency considerations so far, as the focus with the EIR calculations is the energy efficiency in the drive cycle. The energy at the end of drive cycle can be accounted for by adjusting the energy input ratio to

$$
E I R_{a}=\left(E_{\text {in,pump }}-E_{\text {Acc,f }}\right) /\left(E_{\text {in,veh }}+E_{\text {loss }}\right),
$$

with $E_{\text {Acc, } f}$ as the energy content of the accumulator at the end of the drive cycle.

Table 3: Simulation results for accumulator's $S_{o} C_{f}$ and $E I R_{a}$

\begin{tabular}{|l|r|r|}
\hline Drive Cycle & Final state of charge & Adjusted EIR \\
\hline FTP-72 & 0.7671 & $65.39 \%$ \\
\hline NYCC & 0.8524 & $52.44 \%$ \\
\hline
\end{tabular}

As the New York City Cycle is shorter and the accumulator's final state-of-charge is higher, taking the energy content of the accumulator at the end of the drive cycle into account affects the energy considerations for this cycle much more than for the FTP-72 cycle.

\section{Study of parameter variation}

The parameter values used in the simulations presented in chapter $4, \mathrm{SoC}_{\text {low }}=0.71$ and $\mathrm{SoC}_{\mathrm{high}}=0.55$, were chosen based on pressure considerations, in an attempt to allow for complete braking energy recuperation.

Typically, the controller parameterization for specific vehicle configurations is achieved via optimization. In literature, a number of approaches can be found using different optimi- zation algorithms [2][4][5][13]. The results will be influenced by the chosen objectives, the weighing of the multiple objective functions, and underlying drive cycles, amongst others. In order to study the pump controller parameterization, this chapter will instead present the results for the individual objectives and drive cycles.

Figure 4, Figure 5 and Figure 6 show the results for the objectives separately. Cases of $\mathrm{SoC}_{\text {low }}>\mathrm{SoC}$ high are not considered, as with the implemented control strategy this would effectively eliminate the control variable $\mathrm{SoC}_{\text {high }}$, and cause the hydraulic accumulator to always be charged to a predefined state-of-charge. For both drive cycles, the velocity error can be lowered by increasing the control parameters, with the result for the New York City Cycle being affected more by the choice of $\mathrm{SoC}_{\text {high }}$ for a given $\mathrm{SoC}_{\text {low }}$ than the FTP-72 cycle. Analyzing the energy input ratio, little variation can be observed for the FTP-72 cycle, while for the New York City Cycle a tendency towards improvement can be observed for lower values of the control parameters. For a number of outlier parameter pairs, the charging of the accumulator occurs from a rather low state-of-charge to a high one, though, resulting in a low energy input ratio. The adjusted energy input ratio explains this variation through the accumulator energy content at the end of the drive cycle. While there is little difference between EIR and EIR a $_{\mathrm{a}}$ for the FTP-72 cycle, the adjusted energy input ratio for the New York City Cycle is lower, and shows less variation.

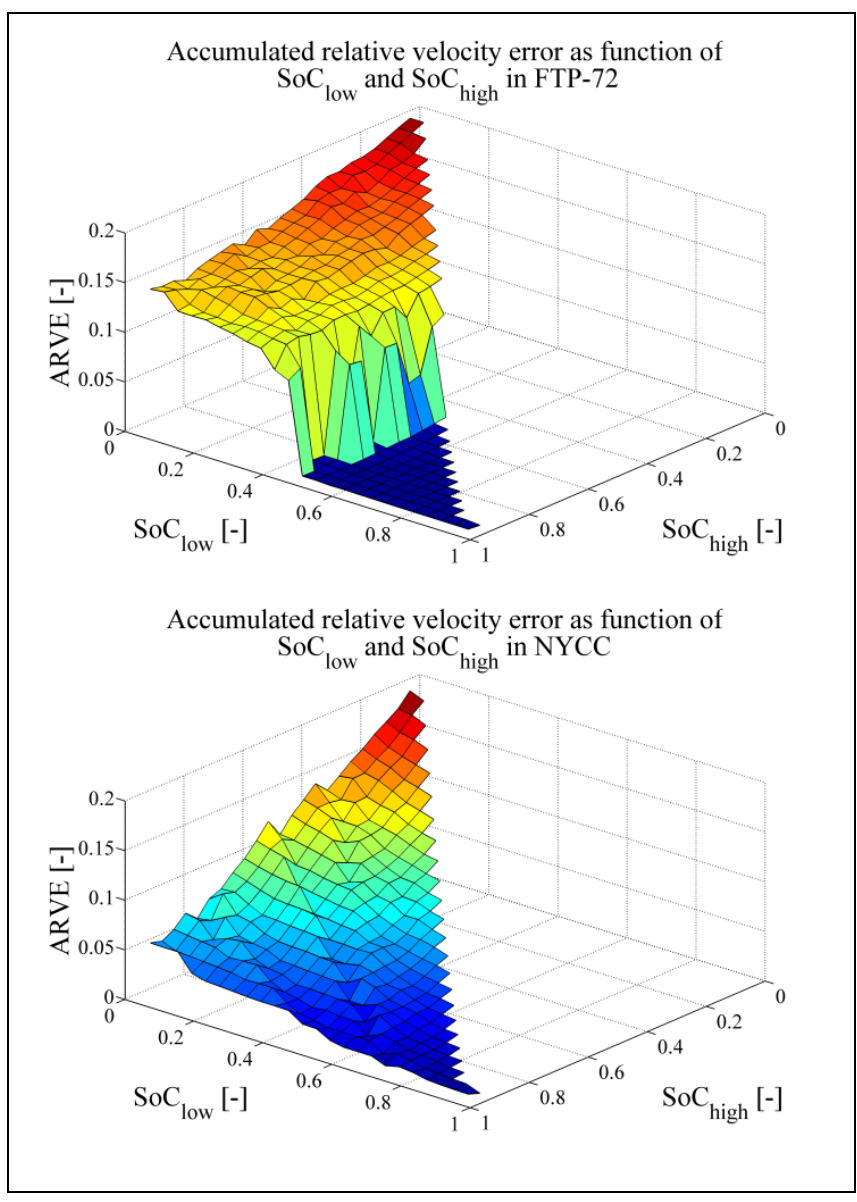

Figure 4: Accumulated relative velocity error as function of $\mathrm{SoC}_{\text {low }}$ and $\mathrm{SoC}_{\text {high }}$ 


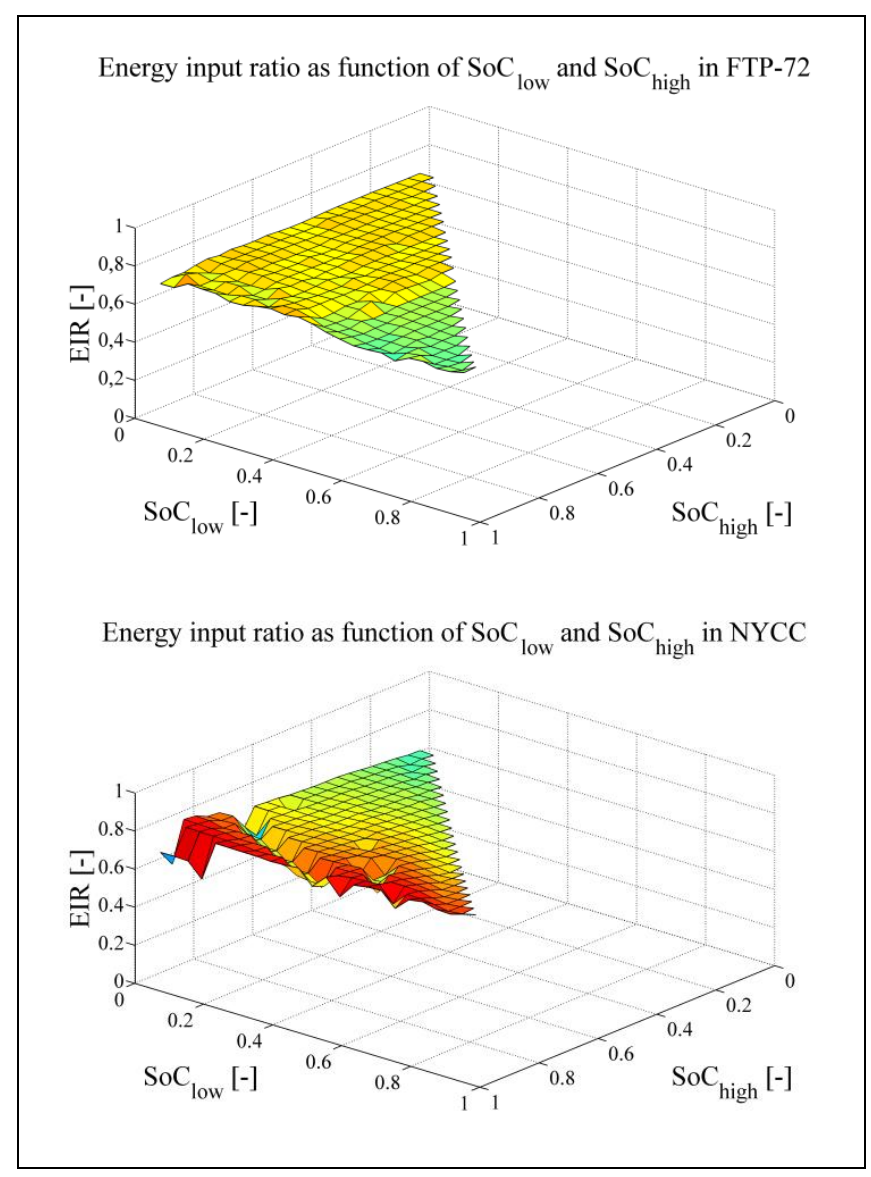

Figure 5: Energy input ratio as function of $\mathrm{SoC}_{\text {low }}$ and $\mathrm{SoC}_{\text {high }}$

\section{Conclusion}

This paper presents a framework for the design of hybrid hydraulic vehicles. This framework has been tested for a series hydraulic hybrid light-weight vehicle. Simulation over two different urban drive cycles has given reasonable results concerning the velocity error, and indicates a potential to reduce the energy input into the system in comparison to running the vehicle with the same transmission, but without the possibility to recuperate energy during braking. Overall, the results show the potential of the framework for more advanced systems.

However, in its current version the model contains a number of significant simplifications which need to be tackled in the future. One extension would be the inclusion of a scalable combustion engine component model, as its fuel consumption characteristics are neglected so far. It could allow for studying downsizing possibilities through hybridization. Furthermore, the current lack of a mechanical gearbox leads to relatively big hydraulic machines, which are not suitable especially for a vehicle of this size.

The goal for the model is to allow a full optimization of the vehicle's drivetrain, including component sizing and controller parameterization, based on a vehicle's specifications and a reference drive cycle. This optimization could also include a limitation for the component sizing to a discrete number of available sizes instead of a continuum of options,

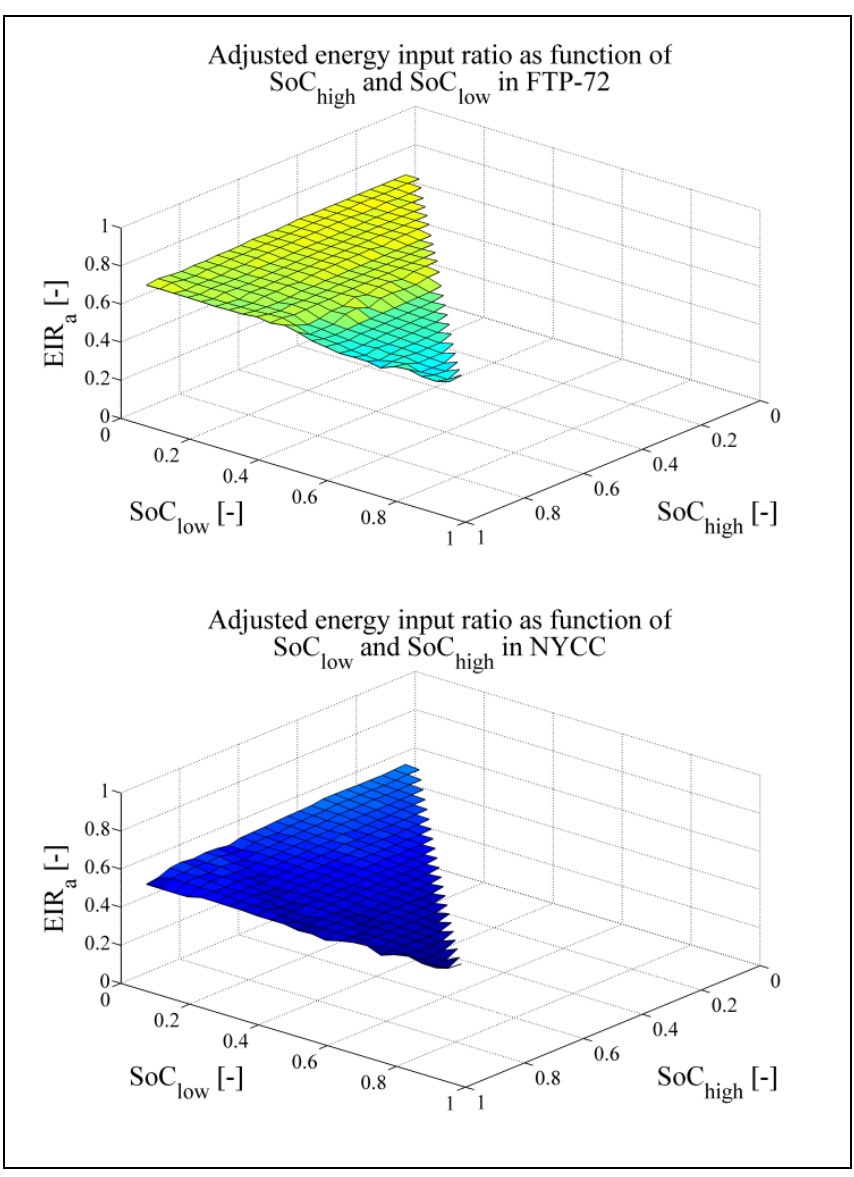

Figure 6: Adjusted energy input ratio as function of $\mathrm{SoC}_{\text {low }}$ and $\mathrm{SoC}_{\text {high }}$

and further respective parameter variations in other components to account for component-size specific limitations.

Similar models will be developed for the parallel and powersplit hydraulic hybrid architectures to run comparisons between the different models. This set of models should be able to give a comprehensive understanding of hydraulic hybrids for future projects.

\section{Nomenclature}

\begin{tabular}{lll}
\hline Designation & Denotation & Unit \\
\hline$A$ & Frontal area of vehicle & {$\left[\mathrm{m}^{2}\right]$} \\
$A R V E$ & $\begin{array}{l}\text { Accumulated relative velocity } \\
\text { error }\end{array}$ & {$[-]$} \\
$c_{d}$ & Aerodynamic drag coefficient & {$[-]$} \\
$c_{d} \cdot A$ & Effective front area & {$\left[\mathrm{m}^{2}\right]$} \\
$c_{f r}$ & Rolling resistance coefficient & {$[-]$} \\
$E_{\text {Acc,f }}$ & Final accumulator energy content & {$[\mathrm{J}]$} \\
$E_{\text {in,pump }}$ & Energy input to pump (system) & {$[\mathrm{J}]$} \\
$E_{\text {in,veh }}$ & Energy input to vehicle & {$[\mathrm{J}]$} \\
$E_{\text {loss }}$ & Energy losses & {$[\mathrm{J}]$}
\end{tabular}




\begin{tabular}{|c|c|c|}
\hline EIR & Energy input ratio & {$[-]$} \\
\hline$E I R_{a}$ & Adjusted energy input ratio & {$[-]$} \\
\hline$i_{\text {diff }}$ & Differential gear ratio & {$[-]$} \\
\hline$M_{v e h}$ & $\begin{array}{l}\text { Vehicle mass (half-loaded, with- } \\
\text { out main hydraulic components) }\end{array}$ & {$[\mathrm{kg}]$} \\
\hline$M_{v e h, t o t a l}$ & Total vehicle mass & {$[\mathrm{kg}]$} \\
\hline$r_{\text {wheel }}$ & Wheel radius & {$[\mathrm{m}]$} \\
\hline$r_{\text {wheel,e }}$ & Effective wheel radius & {$[\mathrm{m}]$} \\
\hline$S o C_{A c c}$ & Accumulator state-of-charge & {$[-]$} \\
\hline$S o C_{f}$ & Final state-of-charge & {$[-]$} \\
\hline$S o C_{l o w}$ & Lower state-of-charge boundary & {$[-]$} \\
\hline So $C_{\text {high }}$ & Higher state-of-charge boundary & {$[-]$} \\
\hline$t_{\text {end }}$ & End time of drive cycle & {$[\mathrm{s}]$} \\
\hline$t_{\text {start }}$ & Start time of drive cycle & {$[\mathrm{s}]$} \\
\hline$T_{v e h, 1}, T_{v e h, 2}$ & Torque on vehicle's axle & {$[\mathrm{Nm}]$} \\
\hline$v_{c}$ & Actual vehicle velocity & {$[\mathrm{m} / \mathrm{s}]$} \\
\hline$v_{r e f}$ & Reference velocity & {$[\mathrm{m} / \mathrm{s}]$} \\
\hline$x_{\max }$ & Total drive cycle distance & {$[\mathrm{m}]$} \\
\hline
\end{tabular}

\section{References}

[1] K-E Rydberg. Energy Efficient Hydraulic Hybrid Drives. Proc. of the 11th Scandinavian International Conference on Fluid Power, Linköping, Sweden, 2009.

[2] Y Yan, G Liu, and J Chen. Integrated Modeling and Optimization of a Parallel Hydraulic Hybrid Bus. International Journal of Automotive Technology, 11(1):97-104, 2010.

[3] S Baseley, C Ehret, E Greif, and M G Kliffken. Hydraulic Hybrid Systems for Commercial Vehicles. Proc. of SAE 2007 Commercial Vehicle Engineering Congress and Exhibition, Rosemont, Illinois, United States, 2007.

[4] C-T Li, and H Peng. Optimal Configuration Design for Hydraulic Split Hybrid Vehicles. Proc. of 2010 American Control Conference, Baltimore, Maryland, United States, 2010.

[5] K A Stelson, J J Meyer, A G Alleyne, and B Hencey. Optimization of a Passenger Hydraulic Hybrid Vehicle to Improve Fuel Economy. Proc. of the 7th JFPS International Symposium on Fluid Power, Toyama, Japan, 2008.

[6] Y J Kim, and Z Filipi. Simulation Study of a Series Hydraulic Hybrid Propulsion System for a Light Truck. Proc. of SAE 2007 Commercial Vehicle En- gineering Congress and Exhibition, Rosemont, Illinois, United States, 2007.

[7] K L Cheong, P Y Li, S Sedler, and T R Chase. Comparison between Input Coupled and Output Coupled Power-split Configurations in Hybrid Vehicles. Proc. of the 52nd National Conference on Fluid Power, Las Vegas, Nevada, United States, 2011.

[8] B Eriksson, P Nordin, and P Krus. Hopsan NG, A C++ Implementation using the TLM Simulation Technique. Proc. of the 51st Conference on Simulation and Modelling, Oulu, Finland, 2010.

[9] K-E Rydberg. On Performance Optimization and Digital Control of Hydrostatic Drives for Vehicle Applications, PhD thesis, Linköping University, 1983.

[10] J D Van de Ven, M W Olson, and P Y Li. Development of a Hydro-Mechanical Hydraulic Hybrid Drive Train with Independent Wheel Torque Control for an Urban Passenger Vehicle. Proc. of International Fluid Power Exhibition, Las Vegas, Nevada, United States, 2008.

[11]F Wang, M I Ramdan, and K A Stelson. Comparison between Hydraulic Hybrid and Electric Hybrid Passenger Vehicle using ADVISOR 2004. Proc. of the 52nd National Conference on Fluid Power, Las Vegas, Nevada, United States, 2011.

[12] United States Environmental Protection Agency. Dynamometer Drive Schedules. Available at: http://www.epa.gov/nvfel/testing/dynamometer.ht m (Accessed 2013-05-23).

[13]H Sun. Multi-objective optimization for hydraulic hybrid vehicle based on adaptive simulated annealing genetic algorithm. Engineering Applications of Artificial Intelligence, 23(1):27-33, 2010. 